\title{
DYNAMICS OF ANTI-ANTIOXIDANT SYSTEM INDICATORS IN THE POSTOPERATIVE PERIOD IN PATIENTS WITH PERIODONTITIS ACCOMPANIED BY DIFFERENT REACTIVATY OF THE ORGANISM
}

DOI: 10.36740/WLek202109128

\author{
Yurii Yu. Yarov' ${ }^{1}$, Iryna I. Tkachenko² \\ 'DONETSK NATIONAL MEDICAL UNIVERSITY, KRAMATORSK, UKRAINE \\ 2POLTAVA STATE MEDICAL UNIVERSITY, POLTAVA, UKRAINE
}

\begin{abstract}
The aim is to study the dynamics of lipid peroxidation and antioxidant protection in the blood of patients with generalized periodontitis accompanied by normo-, hyper- and hyporeactivity of the body after patch surgery.

Materials and methods: 216 people aged 45 between 55 years with a diagnosis of generalized periodontitis of II, III degree of severity, chronic course were examined. Depending on the condition of reactivity of the organism, patients were divided into three groups: the first consisted of people with normoreaction; the second included patients with hyperreaction; the third group was made up by people with hyporeaction. Patients after initial therapy, underwent patch surgery. Blood sampling was performed after surgery on the 1st, 2nd, 4th, 6th and 9th day. The content of diene conjugates, malonic dialdehyde and peroxide hemolysis of erythrocytes, superoxide dismutase activity, catalase, and total antioxidant activity was determined by the biochemical method.

Results: Normoreaction was characterized by two-phase moderate activation of lipid peroxidation with maxima on the 1st and 6 th day against the normalization of the balance of oxidative systems by the end of observations. For hyperreaction pronounced activation of lipid peroxidation (significant increase in the content of diene conjugates and malonic dialdehyde with a maximum on the 1st day) accompanied by depletion of antioxidant protection activity was typical. Hyporeaction was characterized by slow activation of lipid peroxidation (increase in diene conjugates and malonic dialdehyde with a maximum on the 4th day) accompanied by insufficient activity of antioxidant protection.

Conclusion: Correction of altered parameters in patients with generalized periodontitis accompanied by impaired (hyper- and hypo-) reactivity of the body with bringing them to values of normoreactivity is considered to be a condition for optimizing mucosal wound healing after surgery and further stabilization of the periodontal tissues.
\end{abstract}

KEY WORDS: periodontitis, body reactivity, lipid peroxidation, antioxidant system, postoperative period

Wiad Lek. 2021;74(9 p.l):2187-2191

\section{INTRODUCTION}

The importance of lipid peroxidation (LPO) processes in the development of generalized periodontitis has been established $[1,2]$. LPO is a normal metabolism, the physiological role of which is to regulate the function of cell membranes, receptors, prostaglandin synthesis [3]. In response to the prolonged persistence of periodontopathogenic microflora, an inflammatory process develops in periodontal tissues, which is a complex of microcirculatory, hematological, immunological and connective tissue reactions to damage, in which microcirculation disruption provokes tissue hypoxia and activation of free radical oxidation. The level of response to damage is determined by the reactivity of the organism. Experimental studies have shown that in animals with spontaneous periodontitis accompanied by hypercoagulation, LPO processes are enhanced [5]. In the clinic, it has been found out that in periodontitis in the blood of patients there is an accumulation of LPO products due to a significant increase in the level of malonic dialdehyde with a decrease in the concentration of superoxide dismutase and catalase $[6,7]$. The results of the study of total antioxidant activity showed that the values of this parameter in the tissues of the gums in cases of intact periodontitis and generalized periodontitis have significant differences $[8,9]$.

\section{THE AIM}

The aim of this paper was to study the dynamics of lipid peroxidation (diene conjugates, malonic dialdehyde, peroxide hemolysis of erythrocytes) and antioxidant protection (superoxide dismutase, catalase, total antioxidant activity) in the blood of patients with hypertensive hypertoxicity after patch surgery.

\section{MATERIALS AND METHODS}

We examined 216 people ( 82 men and 134 women), aged between 45 and 55 years with a diagnosis of generalized periodontitis of II, III degree of severity. The diagnosis was made on the basis of clinical examination, radiography, determination of periodontal samples in accordance with the International Classification of Diseases ICD-10. Depending on the state of reactivity of the organism, patients 
were divided into three groups: the first one contained patients with normoreaction (132 people, 61\%); the second group consisted of people with hyperreaction (46 people, $21 \%)$; the third one included patients with hyporeaction (38 people, 18\%). The division of patients into groups depending on the condition of reactivity of the organism was performed on the basis of the identified clinical and laboratory differences.

All the patients underwent complex treatment of generalized periodontitis in the amount recommended by the Ministry of Health of Ukraine (Order №566 from 23.11.04). Patients after initial therapy, underwent patch surgery on the upper and lower jaws according to the indications.

Blood sampling was performed after surgery on the 1st, 2nd, 4th, 6th and 9th day in the morning on an empty stomach from the ulnar vein with a volume of $10 \mathrm{ml}$. The content of diene conjugates (DC), malonic dialdehyde (MDA) and erythrocyte peroxide hemolysis (EPH), superoxide dismutase (SOD) activity, catalase (K), total antioxidant activity (TAA) was determined with the help of a biochemical method.

Statistical processing of the obtained digital data was performed using the computer program Statistica 8.0 (STA862D175437Q).

\section{RESULTS AND DISCUSSION}

The results of the study of LPO in the blood of patients with normoreactivity of the body are presented in table I.

After patch surgery, there was an increase in the level of diene conjugates in the blood of patients. The dynamics of the indicator was two-phase with peaks on the 1st and 6th day after the intervention. The first rise in the concentration of DC in the blood was more pronounced. The peak DC values were 1.5 times higher than baseline. On the 2 nd day after the surgery, there was a decrease in the concentration of diene conjugates to baseline. Subsequently, beginning with the 4th day there was a repeated rise in the level of DC with its maximum on the 6th day. The second rise in the content of diene conjugates was less pronounced than the first one. Its peak values were 1.2 times higher than the initial ones. By the end of the observations, there was a tendency for reduction of the concentration of DC. Malonic dialdehyde is a by-product of LPO. After the intervention, an increase in the level of MDA in the blood of patients was determined. On the 1st day, its value was 1.6 times higher than the initial. The dynamics of MDA was similar to that of DC - changes in the concentration of malonic dialdehyde were also biphasic. The maximum values were on the 1st and 6th day after the intervention. The first rise was more pronounced than the second. By the end of the observations, there was a tendency for reduction of the content of MDA. It is important to observe the dynamics of erythrocyte peroxide hemolysis as an indicator that characterizes the resistance of blood cell membranes to the products of lipid peroxidation. After surgery during the first four days, no statistically significant changes were observed. On the 6th day, the value of EPH increased 1.2 times compared with the initial $(\mathrm{p}<0,05)$ with a subsequent decrease until the end of the observation. This dynamics of EPH is a reflection of the stable state of blood cell membranes in patients with GP accompanied by normoreaction.

The most informative indicators of the antioxidant system are the activity of enzymes - superoxide dismutase, catalase and total antioxidant activity (Table II).

The dynamics of the SOD enzyme was two-phase with maximum values on the 1st and 6th day after the intervention, which corresponded to the peak values of the rise in the level of DC and MDA. On the 1st day, the values of SOD activity were 1.3 times higher than the initial level $(p<0.05)$, which is explained by the increase in the content of primary and secondary products of LPO in the blood. The initial increase in the level of superoxide dismutase was replaced by its fall on the 2 nd day with its minimum value on the 4 th day after the intervention. Subsequently, on the 6 th day, the repeated, less pronounced in comparison with the first rise was registered. The SOD values were 1.2 times higher than the primary ones. This dynamics indicates a fairly high activity of antioxidant protection in patients with GP accompanied by normoreactivity of the body. The dynamics of catalase was biphasic with its maximum values on the 1st and 6th day after the intervention. On the 1st day after the surgery, its concentration was 1.6 times higher than the initial value $(\mathrm{p}<0,05)$. On the 2nd day there was a drop in the level of the enzyme to $11.48 \pm 0.28 \mathrm{mcatal} / \mathrm{l}$. On the 4 th day after the intervention, the parameter values remained practically at this level. On the 6th day, the level of catalase increased 1.2 times compared to the initial value with a subsequent decrease in values. However, it should be taken into consideration that normalization of the catalase content did not occur. Even by the end of the observations, the values of the enzyme remained above the initial level $(\mathrm{p}<0,05)$. The dynamics of TAA was characterized by a decline in the level with a subsequent increase. On the 1st day after the intervention, the values of TAA decreased, reaching its minimum on the 4 th day. The value of the indicator was 1.3 below the initial level ( $p>0.05)$. This decrease over time coincided with the reaching the minimum values of catalase. On the 6 th and 9th day, the level of antioxidant protection increased. The indicators were, on average, 1.1 times higher than the initial values ( $p>0.05)$.

The results of determining the indicators of lipid peroxidation in the blood of patients with generalized periodontitis with hyperreactivity are presented in table I. The performed surgery also, as well as in case of normoreaction, led to the increase in the content of DC in blood of patients of this group. It is necessary to take into consideration the higher increase in the concentration of DC during all the stages of the experiment. This indicator was maintained at a significantly incresed level until the end of observations ( $p<0,05)$. The peak values of DC concentration were observed on the 1st and 9th day, significantly exceeding the corresponding values in the first group -1.65 and 1.43 times $(p<0.05)$. The 
Table I. The Content of Diene Conjugates (DC), Malonic Dialdehyde (MDA), Peroxide Hemolysis of Erythrocytes (PHE) in case of normo-, hyper- and hyporeactivity of the body after surgery $(\mathrm{M} \pm \mathrm{SE})$

\begin{tabular}{|c|c|c|c|c|}
\hline \multirow[b]{2}{*}{ Indicators } & \multirow{2}{*}{$\begin{array}{c}\text { Terms of } \\
\text { Observation }\end{array}$} & \multicolumn{3}{|c|}{ Groups of patients } \\
\hline & & $\begin{array}{l}\text { Normoreaction } \\
\quad(n=132)\end{array}$ & $\begin{array}{l}\text { Hyperreaction } \\
\qquad(n=23)\end{array}$ & $\begin{array}{l}\text { Hyporeaction } \\
(n=19)\end{array}$ \\
\hline \multirow{6}{*}{$\begin{array}{l}\text { DC, } \\
\text { c.u. }\end{array}$} & Initially & $2,48 \pm 0,06$ & $2,94 \pm 0,24 \ll$ & $1,90 \pm 0,18 \ll$ \\
\hline & 1st day & $3,80 \pm 0,08 *$ & $4,86 \pm 0,28 * \ll$ & $1,98 \pm 0,21 \ll$ \\
\hline & 2nd day & $2,46 \pm 0,10$ & $4,18 \pm 0,26 * \ll$ & $2,04 \pm 0,19 \ll$ \\
\hline & 4th day & $2,99 \pm 0,09 *$ & $3,69 \pm 0,23 * \ll$ & $2,65 \pm 0,18 * \ll$ \\
\hline & 6th day & $3,02 \pm 0,08 *$ & $3,92 \pm 0,25 * \ll$ & $2,50 \pm 0,21 * \ll$ \\
\hline & 9th day & $1,98 \pm 0,09 *$ & $4,22 \pm 0,25 *$ « & $2,44 \pm 0,19 * \ll$ \\
\hline \multirow{6}{*}{$\begin{array}{c}\text { MDA, } \\
\mu \mathrm{mol} / \mathrm{I}\end{array}$} & Initially & $10,90 \pm 0,92$ & $11,22 \pm 1,32$ & $9,29 \pm 1,38$ \\
\hline & 1 st day & $17,42 \pm 0,58 *$ & $21,04 \pm 1,98 * \ll$ & $9,78 \pm 1,41 \ll$ \\
\hline & 2nd day & $11,18 \pm 0,38$ & $18,96 \pm 1,66{ }^{*} \ll$ & $10,54 \pm 1,69$ \\
\hline & 4th day & $11,79 \pm 0,46$ & $14,37 \pm 1,54 \ll$ & $12,35 \pm 1,48 *$ \\
\hline & 6th day & $13,30 \pm 0,28 *$ & $16,58 \pm 0,60 *$ & $11,45 \pm 1,50$ « \\
\hline & 9th day & $9,08 \pm 0,29$ & $19,04 \pm 1,82 * \ll$ & $10,88 \pm 1,69$ \\
\hline \multirow{6}{*}{$\begin{array}{c}\mathrm{PHE}, \\
\%\end{array}$} & Initially & $9,88 \pm 0,66$ & $12,90 \pm 1,37 \ll$ & $12,79 \pm 1,40 \ll$ \\
\hline & 1st day & $10,25 \pm 0,80$ & $13,05 \pm 1,40$ & $12,48 \pm 1,50$ \\
\hline & 2nd day & $10,14 \pm 0,72$ & $13,12 \pm 1,42$ & $12,64 \pm 1,49$ \\
\hline & 4th day & $10,19 \pm 0,80$ & $19,28 \pm 1,68 * \ll$ & $18,45 \pm 1,58 * \ll$ \\
\hline & 6th day & $12,09 \pm 0,72 *$ & $18,82 \pm 1,69 *$ & $20,85 \pm 1,70 *$ \\
\hline & 9th day & $8,74 \pm 0,62$ & $22,74 \pm 1,90 * \ll$ & $17,88 \pm 1,59 *$ \\
\hline
\end{tabular}

Note: ${ }^{*}-p<0.05$ against the initial values

$«-p<0,05$ against values typical for normoreactivity of the organism

Table II. The activity of superoxide dismutase (SOD), catalase, total antioxidant activity (TAA) in case of normal, hyper- and hyporeactivity of the body after surgery $(\mathrm{M} \pm \mathrm{SE})$

\begin{tabular}{|c|c|c|c|c|}
\hline \multirow[b]{2}{*}{ Indicators } & \multirow{2}{*}{$\begin{array}{c}\text { Terms of } \\
\text { Observation }\end{array}$} & \multicolumn{3}{|c|}{ Groups of Patients } \\
\hline & & $\begin{array}{l}\text { Normoreaction } \\
(n=132)\end{array}$ & $\begin{array}{l}\text { Hyperreaction } \\
\qquad(n=23)\end{array}$ & $\begin{array}{l}\text { Hyporeaction } \\
\qquad(n=19)\end{array}$ \\
\hline \multirow{6}{*}{$\begin{array}{c}\text { SOD, } \\
\text { E / mg protein }\end{array}$} & Initially & $0,120 \pm 0,006$ & $0,147 \pm 0,020 \ll$ & $0,082 \pm 0,012 \ll$ \\
\hline & 1st day & $0,158 \pm 0,008 *$ & $0,187 \pm 0,028 * \ll$ & $0,093 \pm 0,018$ \\
\hline & 2nd day & $0,146 \pm 0,010 *$ & $0,156 \pm 0,022 \ll$ & $0,114 \pm 0,019$ \\
\hline & 4th day & $0,142 \pm 0,007 *$ & $0,150 \pm 0,021 \ll$ & $0,125 \pm 0,018 *$ \\
\hline & 6th day & $0,149 \pm 0,009 *$ & $0,144 \pm 0,020$ & $0,122 \pm 0,021 *$ \\
\hline & 9th day & $0,147 \pm 0,008$ * & $0,170 \pm 0,026$ « & $0,064 \pm 0,019$ « \\
\hline \multirow{6}{*}{$\begin{array}{l}\text { Catalase, } \\
\text { mkatal / I }\end{array}$} & Initially & $12,00 \pm 0,29$ & $15,03 \pm 1,35 \ll$ & $9,19 \pm 1,15 \ll$ \\
\hline & 1st day & $19,18 \pm 0,35 *$ & $21,14 \pm 1,61 * \ll$ & $8,37 \pm 1,18 \ll$ \\
\hline & 2nd day & $11,48 \pm 0,28$ & $16,28 \pm 1,44$ « & $8,14 \pm 1,19 \ll$ \\
\hline & 4th day & $11,37 \pm 0,28$ & $14,10 \pm 1,40$ & $7,95 \pm 1,18 \ll$ \\
\hline & 6th day & $14,43 \pm 0,32 *$ & $14,02 \pm 1,39$ & $7,01 \pm 1,01 * \ll$ \\
\hline & 9th day & $13,20 \pm 0,30 *$ & $17,44 \pm 1,55$ « & $8,03 \pm 1,19 \ll$ \\
\hline \multirow{6}{*}{ TAA, \% } & Initially & $56,8 \pm 7,6$ & $63,7 \pm 20,0$ & $52,7 \pm 18,0$ \\
\hline & 1st day & $54,2 \pm 4,8$ & $60,8 \pm 19,5$ & $51,4 \pm 15,5$ \\
\hline & 2nd day & $47,1 \pm 4,2$ & $57,6 \pm 19,0$ & $50,4 \pm 15,9$ \\
\hline & 4th day & $44,19 \pm 4,8$ & $57,2 \pm 19,0$ & $50,9 \pm 15,0$ \\
\hline & 6th day & $61,0 \pm 5,7$ & $58,0 \pm 19,4$ & $52,5 \pm 15,2$ \\
\hline & 9th day & $60,4 \pm 8,6$ & $59,4 \pm 19,6$ & $51,8 \pm 17,5$ \\
\hline
\end{tabular}

Note: ${ }^{*}-p<0.05$ against the initial values

$«-p<0,05$ against values which are typical for normoreactivity of the organism

content of malonic dialdehyde in the blood of patients with generalized periodontitis of the second group before surgery was $11.22 \pm 1.32 \mu \mathrm{mol} / \mathrm{l}$, which is 1.3 times higher compared to this value with normoreactivity of the body ( $p>0.05)$. After patch surgery, an increase in the level of MDA in patients with GP with hyperreactivity of the body with two maximum values - on the 1st and 9th day, respectively, 1.9 and 1.7 times higher than the initial value $(p<0,05)$. In contrast to the first group, the second peak of MDA concentration occurred three days later. Also, as in the case of the dynamics of DC, it is necessary to pay attention to the higher concentration of MDA during all 
the stages of the experiment in comparison with that of the normoreaction. The intervention led to an increase in EPH, and the dynamics, as in the normoreaction of the organism, was monophasic. However, in contrast to the first group, the maximum value of the indicator was not on the $6 \mathrm{th}$, but on the 9th day. In addition, some significant difference in amplitude values was noted. Thus, EPH in patients of the second group by the end of the observation was 1.8 times higher than the initial level and 2.6 times higher than the corresponding value which is typicl for patients of the first group $(\mathrm{p}<0.05)$. This indicates less resistance of blood cells in patients with GP with hyperreaction to LPO.

The dynamics of antioxidant protection, typical for hyperreactivity of the body are presented in table II. After patch surgery, an increase in the content of superoxide dismutase in the blood of patients with hyperreactivity of the body. However, in contrast to patients with normoreaction, the dynamics of the indicator in this case had the maximum peak values on the 1st and 9th day. In addition, it should be taken into considertion that the amplitude of the values of SOD in all the periods of observation was significantly higher than that of normoreactivity of the organism. Thus, on the 1st day, the level of SOD was 1.27 higher than the initial value and 1.18 higher than the corresponding value, typical for normoreactivity $(\mathrm{p}<0.05)$. During the next day, the activity of superoxide dismutase stabilized, which over time coincides with the maximum content of LPO products in the blood of patients in this group. On the 9th day, the content of SOD in the blood again increased. However, this increase was less pronounced than the first. At the same time, the values of the indicator were 1.16 times lower than the initial ( $p>0.05)$ and "normal" levels $(p<0.05)$. The surgery caused an increase in enzyme activity. The dynamics of the catalase differed from that of patients in the first group and was biphasic with the maximum values on the 1st and 9th day. In addition, the amplitude of catalase values during the observation period significantly exceeded that of normoreactivity of the organism. The minimum value of the indicator was registered on the 6th day, i.e. two days later than in patients with normoreaction. During this period, the value of catalase was 1.07 times lower than the initial level ( $p>0.05)$. On the 9th day, again the value of the indicator 1.16 times increased compared with the initial ( $p>0.05)$ level. It should be taken into consideration that the level of catalase was 1.32 times higher than that of normoreactivity of the organism $(p<0,05)$. After the surgery, there was a decrease in TAA. The minimum value of this indicator was recorded on the 4 th day, when the total antioxidant activity was 1.11 times lower than the initial value ( $p>0.05)$. In the future, TAA, having risen slightly, remained below the initial level.

The results of determination of LPO in the blood of patients with generalized periodontitis with hyporeactivity of the body are presented in table I. The performed surgery also, as well as in case of normoreaction, led to the increase in the content of DC in blood of patients of this group. However, the dynamics of the indicator differed from that of patients of the first group and was monophasic.
On the 1st and 2nd days there was only a tendency for increasing the concentration of primary products and their statistically significant differences from the initial values were not observed ( $p>0.05)$. But at the same time the patients with normoreaction of the body had the first pronounced peak of activity of free radical processes. Subsequently, there was an increase in the concentration of diene conjugates and the maximum values that occurred on the 4th day (the level of DC was 1.4 times higher than the initial, $\mathrm{p}<0,05)$. This peak occurs three days later than in patients of the first group, so the rate of DC rise was lower. Beginning with the 6th day there was a slight decrease in the content of diene conjugates in the blood, but in contrast to patients with GP with normoreactivity of the body, this value remained 1.3 times higher than the initial level until the end of observations $(p<0,05)$. After patch surgery, an increase in the level of MDA in patients with GP accompanied by hyporeactivity of the body was determined. However, the dynamics of the indicator, in contrast to that in the first group, was single-phase with maximum peak values on the 4th day (1.3 times higher than the initial values, $\mathrm{p}<0.05)$. In the first three days there was only a tendency to increase the concentration of malonic dialdehyde. By the end of observations, the level of the indicator fell, remaining 1.2 times higher than the initial level ( $p>0.05)$. The intervention led to an increase in $\mathrm{EPH}$, and the dynamics, as in case of the normoreaction of the organism, was monophasic. The maximum value was registered on the 6th day, which over time coincides with that in patients with normoreaction, but differs significantly in amplitude. Thus, EPH in this period was 1.6 times higher than the initial level and 1.7 times higher than the corresponding value in patients of the first group $(p<0,05)$. This indicates less resistance of blood cells in patients with GP accompanied by hyporeactivity of the body to free radical processes. EPH decreased slightly, but even on the 9th day remained 1.4 and 2.1 times higher, respectively, the initial value and that of normoreaction $(\mathrm{p}<0,05)$.

The dynamics of antioxidant protection in the blood of patients with GP accompanied by hyporeactivity of the body are presented in table II. After patch surgery, an increase in the content of superoxide dismutase in the blood of patients with hyporeactivity of the body was observed. However, in contrast to patients of the first group, the dynamics of the indicator in this case was monophasic with the maximum peak value on the 4th day, when the level of SOD was 1.5 times higher than the initial value $(p<0.05)$. Over the next two days, the activity of superoxide dismutase stabilized, which over time coincides with the maximum content of LPO products in the blood of patients in this group. On the 9th day, the content of SOD in the blood decreased sharply. In this case, the values of the indicator were 1.3 and 2.1 times lower, respectively, the initial $(p>0.05)$ and "normal" levels $(p<0.05)$. At that time the patients of the first group were observed to have an increase in activity of SOD in comparison with the lowered initial level. The dynamics of the catalase did not 
differ significantly from that patients of the first group and was monophasic with a maximum value on the 1st day. The minimum value of the indicator was registered on the 6th day, i.e. two days later than in patients with normoreactivity of the organism. During this period, the value of catalase was 1.3 times lower than the initial level $(p<0,05)$. This decrease in activity over time coincided with the maximum content of primary and secondary products of LPO in the blood of patients in this group. Subsequently, the catalase activity increased without reaching the initial level by the end of observations. On the 9th day, the values of the indicator remained 1.1 times lower than the initial ( $p>0.05)$. After the surgery, there was a decrease in TAA. The minimum value of this indicator was registered on the 2nd day, the total antioxidant activity was 1.1 times lower than the initial value $(p>0.05)$. The level remained at this level for the next two days. In the future, TAA, having risen slightly, remained below the initial level.

Our studies confirm the important role of free radical processes in postoperative wound healing. We have shown, that the nature of changes in the pro- and antioxidant system in the postoperative period in patients with generalized periodontitis is different in amplitude and timing depending on different conditions of reactivity of the organism. Correction of altered parameters in patients with generalized periodontitis accompanied by impaired (hyper- and hypo-) reactivity of the body with bringing them into values which are typical for normoreactivity is considered to be a condition for optimizing mucosal wound healing after surgery and further stabilization of the periodontal tissues.

\section{CONCLUSIONS}

The analysis of the study results showed that the normoreaction was characterized by two-phase moderate activation of lipid peroxidation with its maximum on the 1st and 6th day accompanied by normalization of the balance of oxidative systems by the end of the observations. The condition of hyperreaction is characterized by pronounced activation of lipid peroxidation (significant increase in the content of diene conjugates and malonic dialdehyde with its maximum on the 1st day) accompanied by depletion of antioxidant protection activity. Slow activation of lipid peroxidation (increase in diene conjugates and malonic dialdehyde with its maximum on the 4th day) accompanied by insufficient activity of antioxidant protection is typical for hyporeaction .

\section{REFERENCES}

1. Pashaev A.CH., Gasanov V.M., Gusejnova S.T. i dr. Analiz faktorov riska vospalitel'nyh zabolevanij parodonta [Analysis of risk factors for inflammatory periodontal diseases ]. Suchasna stomatologiya. 2020;1:39-41. (In Russian).

2. Moroz K. A. Rol' peroksidnoï oksidaciï lipidiv u rozvitku patologiï parodonta [The role of lipid peroxidation in the development of periodontal pathology]. Eksperim. ta klinich. fiziologiya i biohimiya. 2004; 2: 87 - 91. (In Ukrainian).
3. Chapple I. L.C. Reactive oxygen species and antioxidants in inflammatory diseases. J. Clin. Periodontol. 2007; 24: 287-296.

4. Ward Peter A., Warren Jeffrey S., Johnson Kent S. Oxygen radicals, inflammation and tissue injury. Free Radic. Biol. and Med. 2008; 5:403-408.

5. Nazaryan R.S., Nikitchenko YU.V. Prooksidantno-antioksidantnij balansu krovi i tkaninah parodonta shchuriv pri hronichnij diï nezbalansovanogo faktichnogo racionu [Prooxidant-antioxidant balance in the blood and periodontal tissues of rats with chronic exposure to unbalanced actual diet]. Odes'kij medich. zhurnal. 2004;6(86):12 - 13. (In Ukrainian).

6. Samojlenko A.V., Gorshkova A. Porivnyal'na harakteristika likuvannya pacientiv hvorih na hronichnij generalizovanij parodontit na tli znizhennya antioksidantnogo zahistu organizmu [Comparative characteristics of the treatment of patients with chronic generalized periodontitis on the background of reduced antioxidant protection of the body]. Suchasna stomatologiya. 2020;1:.52-57. (In Ukrainian).

7. Yarova S. P., Osipenkova T. S. Efektivnist' metodu diferencijnoï korekciï perekisnogo okislennya lipidiv i antioksidantnogo zahistu v kompleksnomu likuvanni generalizovanogo parodontitu [The effectiveness of the method of differential correction of lipid peroxidation and antioxidant protection in the complex treatment of generalized periodontitis]. Visnik stomatologiï. 2001;1: 28 - 31. (In Ukrainian).

8. Pinchuk V.A., Sylenko G.Y., Sylenko Y.I., et al. Features of clinical manifestations, free radical, coagulation and aggregation properties of blood in patients with craniocerebral trauma. Wiad. Lek. 2019;72(4): 539-542.

9. Sylenko Ju.I., Perepelova T.V., Sylenko B.Ju., et al. The reactions of lipid's free radical oxidation, hemocoagulant properties of oral fluid in patients with galvanic currents in the mouth. Wiad. Lek.. 2018;71(4):879-882.

The work is a fragment of the research initiative of the Department of Stomatology №2 «Studying the Influence of Oral Fluid and Biofilm on the Development of Diseases of the Oral Cavity". State registration number 0121U107494.

ORCID and contributionship:

Yuriy Yu. Yarov: 0000-0002-2867-9866 ${ }^{B-D}$

Iryna I. Tkachenko: 0000-0001-8243-8644 ${ }^{A, E, F}$

\section{Conflict of interest:}

The Authors declare no conflict of interest.

\section{CORRESPONDING AUTHOR \\ Yuriy Yu. Yarov \\ Donetsk National Medical University \\ Mashonobudivnikov Boulevard, 39, \\ Kramatorsk, 84404, Ukraine \\ e-mail: Kaf.stomatologii2@ukr.net}

Received: 29.05.2021

Accepted: 25.08 .2021

A - Work concept and design, B - Data collection and analysis, C - Responsibility for statistical analysis, D -Writing the article, $\mathbf{E}-$ Critical review, $\mathbf{F}$ - Final approval of the article 